\title{
Acúmulo foliar de enxofre e suas relações com alterações no crescimento de plantas jovens de Tibouchina pulchra Cogn. (Melastomataceae) expostas nas proximidades do polo industrial de Cubatão, SP1
}

\author{
ANNA V. SZABO ${ }^{2}$, MARISA DOMINGOS ${ }^{3,5}$, MIRIAN C.S. RINALDI ${ }^{3}$ e WELINGTON B.C. DELITTI ${ }^{4}$
}

(recebido: 7 de agosto de 2002; aceito: 14 de agosto de 2003)

\begin{abstract}
Foliar sulfur accumulation and its relations with changes in growth of saplings of Tibouchina pulchra Cogn. (Melastomataceae) exposed around the industrial complex of Cubatão, SP, Brazil). The aim of this study was to verify, under field conditions, if $\mathrm{SO}_{2}$ imissions from the industrial complex of Cubatão, since absorbed and accumulated in leaves, may cause changes in the growth of saplings of T. pulchra. The study was performed along 1997 by exposing potted plants during three consecutive periods of 16 weeks in three sites: Pilões river valley (RP; under low levels of $\mathrm{SO}_{2}$ ); Caminho do Mar and Mogi river valley (CM and VM respectively; under high $\left.\mathrm{SO}_{2}\right)$. After each exposure, foliar accumulation of sulfur and changes in growth and biomass parameters, besides the statistical relations among them, were determined. Significant foliar accumulation of sulfur was observed in plants exposed at CM (exposures 1 to 3 ) and at VM (exposures 2 and 3). The growth of plants from both polluted sites was strongly modified, especially height and number of leaves and branches. Changes in biomass of leaves, stem+branches and roots were rarely detected, but significant reductions in the root/shoot ratio were observed in plants exposed at CM and VM (exposures 1 and 3). The decrease in height and in stem+branch and root biomass (exposure 2) and the increase in height and in leaf and branch production, as well as the decrease in number of leaves (main stem), in root biomass and in root/shoot ratio (exposure 3 ) were significantly explained by the accumulation of sulfur in leaves $(\mathrm{p}<0.01)$.
\end{abstract}

Key words - biomass, Cubatão, foliar sulfur accumulation, sulfur dioxide, Tibouchina pulchra

RESUMO - (Acúmulo foliar de enxofre e suas relações com alterações no crescimento de plantas jovens de Tibouchina pulchra Cogn. (Melastomataceae) expostas nas proximidades do polo industrial de Cubatão, SP). Objetivou-se verificar, em condições de campo, até que ponto a presença de $\mathrm{SO}_{2}$ no ar, na região do polo industrial de Cubatão, pode causar alterações no crescimento de plantas jovens de T. pulchra. Durante 1997, expuseram-se as plantas envasadas por três períodos consecutivos de 16 semanas, em três locais: vale do rio Pilões (RP; sob baixos níveis de $\mathrm{SO}_{2}$ ); Caminho do Mar e vale do rio Mogi (CM e VM respectivamente; sob baixos níveis de $\mathrm{SO}_{2}$ ). Após cada exposição, o acúmulo foliar de enxofre e alterações em variáveis de crescimento e de biomassa foram determinados e as relações entre essas variáveis foram testadas estatisticamente. Verificou-se acúmulo foliar significativo de enxofre nas plantas do CM (exposições 1 a 3 ) e nas do VM (exposições 2 e 3 ). Os padrões de crescimento das plantas foram modificados nas plantas do CM e VM, destacando-se altura, número de folhas e de ramos. A biomassa variou pouco entre as plantas dos três locais, mas houve redução significativa na razão raízes/parte aérea nas plantas dos locais poluídos (exposições 1 e 3). A desaceleração do crescimento em altura e a diminuição em biomassa de caules+ramos e de raízes (exposição 2) e a intensificação do crescimento em altura, da produção de folhas e da ramificação, e a redução no número de folhas no caule principal, na biomassa de raízes e na razão raízes/parte aérea (exposição 3 ) foram significativamente explicadas pelo acúmulo foliar de enxofre $(\mathrm{p}<0,01)$.

Palavras-chave - acúmulo foliar de enxofre, biomassa, Cubatão, dióxido de enxofre, Tibouchina pulchra

\section{Introdução}

A Mata Atlântica que recobre a Serra do Mar, na região de Cubatão, São Paulo, vem sofrendo grande

1. Parte da dissertação de mestrado de A.V. Szabo.

2. Centro de Recursos Ambientais - CRA, R. Rio São Francisco, 1, 40425-060 Salvador, BA, Brasil.

3. Instituto de Botânica, Seção de Ecologia, Caixa Postal 4005, 01061-970 São Paulo, SP, Brasil.

4. Universidade de São Paulo, Instituto de Biociências, Departamento de Ecologia Geral, Rua do Matão, Travessa 14, 321, 05508-900 São Paulo, SP, Brasil.

5. Autor para correspondência: mmingos@ig.com.br impacto, ocasionado por uma variedade de poluentes atmosféricos, produzido pelo complexo industrial ali instalado a partir da década de 50. Atualmente, existem mais de 20 indústrias com diversos ramos de atividade, emitindo poluentes como materiais particulados, fluoretos, amônia, óxidos de nitrogênio e de enxofre (Alonso \& Godinho 1992).

Tais contaminantes atmosféricos provocam mudanças químicas, fisiológicas, metabólicas e morfológicas nas plantas, que podem resultar em alterações em seus padrões de crescimento e na dinâmica de populações e de comunidades vegetais expostas. Em casos extremos, proporcionam a morte 
de indivíduos e até o desaparecimento de espécies sensíveis (Schmieden \& Wild 1995).

Apesar de ser um elemento essencial, o enxofre pode ser muito tóxico às plantas. Por isso, o aumento acentuado das emissões antropogênicas de compostos sulfurosos, principalmente óxidos de enxofre, em função da queima de combustíveis fósseis, tem causado danos às florestas há muito tempo (Dmuchowski \& Bylnerowicz 1995, Manninen et al. 1996, Manninen \& Huttunen 2000).

A maior parte do enxofre assimilado pelas plantas é absorvida do solo pelas raízes, na forma de sulfato. Porém, as plantas podem acumular o enxofre como resultado da absorção foliar de óxidos de enxofre existentes no ar. $\mathrm{O} \mathrm{SO}_{2}$ contido na atmosfera, o mais abundante entre os óxidos de enxofre, é absorvido prontamente pelas plantas através dos estômatos (Manninen et al. 1996, Manninen \& Huttunen 2000).

$\mathrm{O} \mathrm{SO}_{2}$ absorvido pelas plantas provoca muitos efeitos bem estabelecidos, geralmente resultantes do acúmulo foliar de enxofre. São observadas, entre outros efeitos, alterações no movimento de estômatos, inibição de várias etapas da fotossíntese e da atividade de diversas enzimas (Slovik et al. 1995, 1996, Deepak \& Agrawal 1999, 2001). Essas, por sua vez, resultam em mudanças nos padrões de crescimento e na arquitetura das plantas, tais como alterações nas taxas de senescência de folhas, na ramificação, na área foliar específica, na altura e nos padrões de alocação de biomassa, entre outros aspectos (Fulford \& Murray 1990, Clarke \& Murray 1990, Murray et al. 1992, Dodd \& Doley 1998, Deepak \& Agrawal 1999, 2001). O retardamento no crescimento e a redução do acúmulo de biomassa, como resultado do aumento da absorção de $\mathrm{SO}_{2}$, podem, também, ser conseqüências da utilização de fotoassimilados para ações de reparo e desintoxicação celulares (Deepak \& Agrawal 2001).

Algumas espécies vegetais, por mostrarem acúmulo foliar de enxofre e alterações em seus processos vitais muito evidentes, previsíveis e mensuráveis, quando expostas em ambiente contaminado por $\mathrm{SO}_{2}$, podem ser utilizadas como bioindicadoras do potencial fitotóxico desse poluente, fornecendo, em última análise, informações sobre a qualidade do ambiente (Dmuchowski \& Bylnerowicz 1995). Tais espécies bioindicadoras podem ser introduzidas de maneira uniforme nesse ambiente, controlando-se variáveis, como solo, idade da planta e condições de exposição. Esta abordagem metodológica é denominada bioindicação ativa (Klumpp et al. 2001). Nesse caso, o acúmulo foliar de enxofre, resultante da absorção estomática, é uma reação indicadora inquestionável da contaminação do ar por compostos de enxofre (Dmuchowski \& Bylnerowicz 1995, Klumpp et al. 2001, Krupa \& Legge 2001).

A espécie arbórea Tibouchina pulchra Cogn., por possuir ampla representação na Mata Atlântica que recobre a Serra do Mar, no Estado de São Paulo, ocorrendo inclusive nos locais mais atingidos pela poluição aérea de Cubatão, tem sido utilizada com sucesso em diversos estudos na região, empregando-se técnicas de bioindicação, visando a avaliar a situação de estresse a que está submetida a vegetação natural ao redor do complexo industrial (Klumpp et al. 1996, 2000, 2002, Domingos et al. 1998, Moraes et al. 2000).

Por um lado, tais estudos mostraram que plantas jovens de T. pulchra expostas em locais poluídos por $\mathrm{SO}_{2}$ sempre acumularam enxofre em suas folhas, supondo-se, portanto, que esse poluente pode ser potencialmente tóxico às plantas. Por outro lado, através de medidas físico-químicas das concentrações aéreas de $\mathrm{SO}_{2}$ e de comparações com os padrões de qualidade do ar vigentes, o órgão estadual responsável pelo controle de qualidade ambiental (Cetesb) sempre afirma que a emissão de $\mathrm{SO}_{2}$ no ar está totalmente controlada em todo o Estado de São Paulo, não causando mais nenhum efeito negativo sobre os seres vivos (Alonso \& Godinho 1992). No presente estudo, em função desses dois aspectos antagônicos, pretendeu-se verificar, em condições de campo e utilizando novamente técnicas de bioindicação ativa, até que ponto a presença de $\mathrm{SO}_{2}$ no ar, na região de Cubatão, uma vez absorvido, pode estar causando alterações no crescimento de plantas jovens de T. pulchra e, portanto, provavelmente impondo riscos às plantas no entorno do complexo industrial.

$\mathrm{O}$ estudo foi realizado em locais mais e menos atingidos pela poluição por dióxido de enxofre, determinando-se estatisticamente as relações entre o acúmulo foliar de enxofre e alterações em parâmetros de crescimento e na distribuição de biomassa.

\section{Material e métodos}

O presente estudo foi desenvolvido ao longo do ano de 1997, adotando-se os princípios da bioindicação ativa. Realizaram-se três experimentos de exposição de plantas jovens de Tibouchina pulchra Cogn. (Melastomataceae) ao ambiente de três locais situados no sopé da Serra do Mar, no município de Cubatão, entre $23^{\circ} 45^{\prime}$ e $23^{\circ} 55^{\prime}$ de latitude $\mathrm{S}$ e $46^{\circ} 15^{\prime}$ e $46^{\circ} 30^{\prime}$ de longitude $\mathrm{W}$ (figura 1 ). Os experimentos de exposição tiveram a duração de 16 semanas cada (tabela 1) e foram realizados consecutivamente. Para cada experimento, 


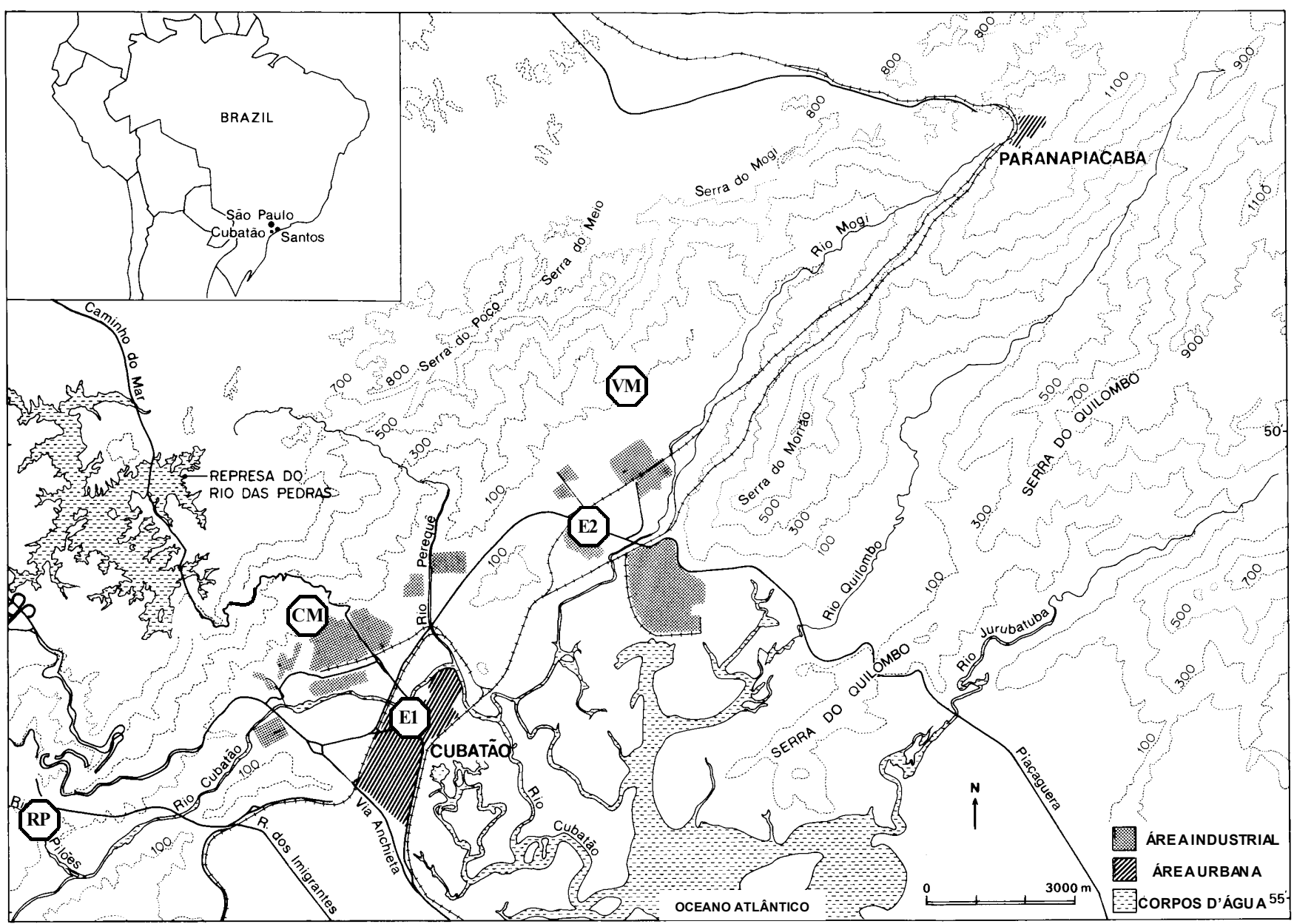

Figura 1. Mapa mostrando a localização das áreas experimentais na Serra do Mar (vale do rio Pilões: RP; Caminho do Mar: CM; vale do rio Mogi: VM) e das estações de monitoramento da qualidade do ar da Cetesb (E1 e E2), em relação ao Pólo Industrial de

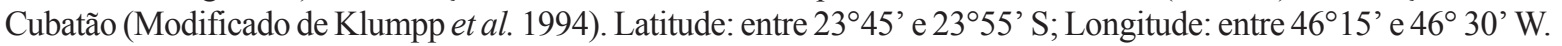

Figure 1. Map showing the location of the experimental sites at Serra do Mar (Pilões river valley: RP; Sea road: CM; Mogi river valley: VM) and of the monitoring stations of air quality of Cetesb (E1 and E2), in relation to the Industrial Complex of Cubatão (modified of Klumpp et al. 1994). Latitude: between $23^{\circ} 45^{\prime}$ and $23^{\circ} 55^{\prime} \mathrm{S}$; Longitude: between $46^{\circ} 15^{\prime}$ and $46^{\circ} 30^{\prime} \mathrm{W}$.

uniformizaram-se, na medida do possível, as variáveis de exposição nos diferentes locais, procurando-se eliminar fatores que pudessem interferir na interpretação dos resultados. Dessa forma, em cada período de exposição, as plantas expostas nos locais de estudo tinham a mesma idade, eram cultivadas em solo de mesma origem e eram expostas a oscilações climáticas similares. Sombreamento, posicionamento dos suportes para as plantas em relação à rota do sol e irrigação também eram uniformes. Todos esses cuidados para uniformização de cada exposição seguiram as recomendações propostas por Arndt \& Schweizer (1991), para o emprego de técnicas de bioindicação ativa em regiões tropicais e sub-tropicais.

Antes de cada exposição, as plantas jovens de T. pulchra eram adquiridas em tubetes no viveiro da Cesp/Paraibuna, sendo provenientes do mesmo lote de produção e, dessa forma, tendo a mesma idade inicial, cerca de seis meses entre a germinação das sementes e a obtenção da muda. No início das exposições, as plantas tinham, em média, $30 \mathrm{~cm}$ de altura (variando entre 28 e $34 \mathrm{~cm}$ nos diferentes experimentos), 10 folhas (variando entre 8 e 11) e nenhuma ramificação.

Em cada exposição, 30 indivíduos jovens foram transplantados para vasos plásticos de 1,5 L com solo típico de Floresta Atlântica retirado da sede do Instituto de Botânica em São Paulo, muito ácido $(\mathrm{pH}=3,3)$ e pobre em nutrientes, situação à qual a espécie está perfeitamente adaptada. Dez vasos foram levados a cada um dos três locais de estudos e colocados em suportes de alumínio, sobre reservatórios plásticos de água. Esses suportes foram instalados a pleno sol, cobertos com tela sombreadora $(50 \%)$ e direcionados, em sua face mais larga, no sentido norte-sul, uniformizando, assim, a incidência luminosa sobre as plantas. Cordões de 
Tabela 1. Concentrações médias, máximas diárias $(\mathrm{MD})$ e máximas horárias $(\mathrm{MH})$ de dióxido de enxofre $\left(\mu \mathrm{g} . \mathrm{m}^{-3}\right)$, registradas nas estações de monitoramento da qualidade do ar da Cetesb, indicadas como E1 e E2 na figura 1 e próximas, respectivamente, aos locais de exposição CM e VM, assim como precipitação acumulada $(\mathrm{P}-\mathrm{mm})$ e médias dos valores máximos e mínimos de temperatura $\left(\mathrm{T}-{ }^{\circ} \mathrm{C}\right)$ e de umidade relativa (UR - \%), em Cubatão/SP, para cada período de exposição.

Table 1. Mean, daily maximum (MD) and hourly maximum (MH) concentrations of sulfur dioxide ( $\mu$ g. $\left.\mathrm{m}^{-3}\right)$, registered in the monitoring stations of air quality of Cetesb indicated as E1 and E2 in the figure 1 and near to $\mathrm{CM}$ and VM exposure sites respectively, as well as accumulated precipitation $(\mathrm{P}-\mathrm{mm})$ and mean values of maximum and minimum teperatures $\left(\mathrm{T}-{ }^{\circ} \mathrm{C}\right)$ and of relative humidity (UR - \%), in Cubatão/SP, for each exposure period.

\begin{tabular}{|c|c|c|c|c|c|c|c|c|c|c|c|c|}
\hline \multirow[t]{3}{*}{ Exposição } & \multirow[t]{3}{*}{ Períodos (1997) } & \multicolumn{6}{|c|}{$\mathrm{SO}_{2}{ }^{a}$} & \multicolumn{5}{|c|}{ Condições climáticas } \\
\hline & & \multicolumn{3}{|c|}{ E1 } & \multicolumn{3}{|c|}{ E2 } & \multirow[t]{2}{*}{$\mathrm{P}^{b}$} & \multicolumn{2}{|c|}{$\mathrm{T}^{c}$} & \multicolumn{2}{|c|}{$\mathrm{UR}^{c}$} \\
\hline & & Média & MD & $\overline{\mathrm{MH}}$ & Média & $\mathrm{MD}$ & $\overline{\mathrm{MH}}$ & & Max. & Min. & Max. & Min \\
\hline 1 & $13 / 01-05 / 05$ & 24 & 85 & 532 & 12 & 77 & 147 & 798 & 29,8 & 20,6 & 100 & 72 \\
\hline 2 & $05 / 05-25 / 08$ & 39 & 91 & 278 & 20 & 124 & 313 & 520 & 26,3 & 16,8 & 97 & 67 \\
\hline 3 & $25 / 08-15 / 12$ & $-d$ & $-d$ & $-d$ & 4 & 57 & 384 & 1036 & 28,3 & 20,5 & 98 & 76 \\
\hline
\end{tabular}

${ }^{a}$ valores obtidos nos boletins diários da Cetesb ${ }^{b}$ dados fornecidos pela Empresa Metropolitana de Águas e Energia S.A. (Estação Henry Borden); ${ }^{c}$ dados fornecidos pela Indústria Carbocloro; ${ }^{d}$ dados não disponíveis.

náilon colocados no fundo do vaso em contato com o solo, em uma extremidade, e mergulhados nos reservatórios de água na extremidade oposta, propiciaram irrigação uniforme e adequada às plantas.

Os três locais de estudo estão situados em altitudes similares e estão sob as mesmas variações mesoclimáticas ao longo do ano, diferindo, no entanto, quanto à influência da poluição aérea.

O primeiro local, considerado como de referência, está situado no vale do rio Pilões (RP - figura 1), a uma altitude de $40 \mathrm{~m}$. Os poluentes aéreos estão presentes em baixas concentrações e se originam principalmente do trânsito de veículos da Rodovia Imigrantes, que liga a cidade de São Paulo ao litoral sul. Barreiras geográficas e a localização fora da direção predominante dos ventos evitam que os poluentes emitidos pelo complexo industrial atinjam o vale do Pilões (Jaeschke 1997). De acordo com esse autor, a concentração média de $\mathrm{SO}_{2}$ no ar, nessa região, para o período de 19911995 , foi de $6,7 \mu \mathrm{m} . \mathrm{m}^{-3}$.

O segundo local de estudo está situado na base da rodovia Caminho do Mar (CM - figura 1), antiga estrada que ligava a cidade de São Paulo à Baixada Santista, a uma altitude de $80 \mathrm{~m}$, nas proximidades das indústrias petroquímicas do complexo industrial. Dessa forma, a vegetação local está sob a influência principalmente de imissões de óxidos de enxofre e de nitrogênio e de compostos orgânicos, assim como de poluentes secundários como ozônio e nitrato de peroxiacetila (Alonso \& Godinho 1992, Klumpp et al. 1994, Jaeschke 1997). A concentração média de $\mathrm{SO}_{2}$ no ar, entre 1991 e 1995, foi de 18,1 $\mu \mathrm{g} \cdot \mathrm{m}^{-3}$ (Jaeschke 1997).

O último local de estudo está situado na entrada do vale do rio Mogi (VM - figura 1), a uma altitude de $20 \mathrm{~m}$, nas proximidades de várias indústrias, entre as quais, as de fertilizantes e outros produtos químicos, de cimento e de produção de aço. Portanto, a vegetação local está submetida a altas imissões de óxidos de enxofre e nitrogênio, amônia, fluoretos, materiais particulados (Alonso \& Godinho 1992, Klumpp et al. 1994, Jaeschke 1997). Nesse local, Jaeschke (1997) registrou, em média para o período de 1991-1995, $25,6 \mu \mathrm{g} \cdot \mathrm{m}^{-3} \mathrm{de} \mathrm{SO}_{2}$.

As concentrações de $\mathrm{SO}_{2}$ disponíveis para o ano de estudo (1997) foram levantadas junto a duas estações de monitoramento existentes em Cubatão, incluídas na rede telemétrica da Cetesb, órgão estadual responsável pelo programa de controle da qualidade do ar de São Paulo (tabela 1). Essas estações estão localizadas no centro de Cubatão e no Bairro Vila Parisi, a cerca de $2 \mathrm{~km}$ respectivamente da Refinaria Presidente Bernardes, próxima ao sítio de exposição CM (E1 - figura 1) e da indústria de fertilizantes Ultrafértil, próxima a VM(E2 - figura 1). Foi feito o levantamento apenas das concentrações do $\mathrm{SO}_{2}$, em virtude deste gás predominar entre os compostos contendo enxofre emitidos pelo complexo industrial de Cubatão. As maiores médias e máximas diárias de concentração foram observadas durante a segunda exposição, nas duas estações de monitoramento, período em que foi registrado o menor índice pluviométrico (inverno). No entanto, os maiores picos horários de concentração foram verificados durante as exposições 1 e 3 , nas estações E1 e E2, respectivamente. As concentrações médias de $\mathrm{SO}_{2}$ foram mais altas na estação de monitoramento situada próxima ao Caminho do Mar (E1). Ao longo de todo o ano de estudo, o padrão primário nacional de qualidade do ar para $\mathrm{SO}_{2}$ (média diária de $365 \mu \mathrm{mg} . \mathrm{m}^{-3}$ e anual de $80 \mu \mathrm{g} . \mathrm{m}^{-3}$; Cetesb 2001) não foi ultrapassado em ambos os locais poluídos.

As condições climáticas em Cubatão, ao longo de 1997, foram típicas para a região, sendo quantificados $2.354 \mathrm{~mm}$ de precipitação anual, e estimados valores médios anuais das 
máximas e mínimas de temperatura de $28,1^{\circ} \mathrm{C}$ e $19,3{ }^{\circ} \mathrm{C}$ e das máximas e mínimas de umidade relativa de $98 \%$ e $72 \%$, respectivamente. $\mathrm{O}$ volume de precipitação foi menor durante os meses de inverno (abrangendo a exposição 2) e maior durante os meses de verão e primavera (exposições 1 e 3). As menores médias de temperatura foram registradas durante a segunda exposição, enquanto as maiores foram medidas nas outras duas exposições. A umidade relativa foi alta ao longo de todo o ano de estudo (tabela 1).

Após cada exposição, foram calculados os incrementos em altura e em número total de folhas, a partir de dados obtidos no início e final do experimento. Número final de folhas no caule principal e de ramos foi, também, avaliado. Folhas, caule+ramos e raízes foram secos em estufa $\left(70^{\circ} \mathrm{C}\right.$, em média), até atingirem peso constante e, então, pesados para obtenção da biomassa seca. Foi estimada a razão entre biomassa de raízes e biomassa da parte aérea (soma da biomassa de folhas e de caule+ramos).

Posteriormente, realizou-se a digestão nítrico-perclórica das folhas moídas e a concentração foliar de enxofre foi determinada por turbidimetria nos extratos resultantes (Butters \& Chenery 1959). Análises concomitantes de amostra foliar padrão (folhas de macieira - NIST 1515) e a obtenção de concentrações de enxofre próximas à esperada atestaram a precisão da técnica analítica empregada.

Considerando as variações nas concentrações de poluentes no ar e no clima ao longo do estudo (tabela 1), os resultados obtidos em cada exposição foram tratados independentemente. Assim, a comparação estatística foi feita somente através de análise de variância (teste F). Os dados relativos à biomassa de folhas (exposição 1), às concentrações de enxofre e ao número de folhas no caule principal (exposição 3), por não apresentarem distribuição normal e/ou homogeneidade de variâncias, foram transformados para log na base 10 antes da aplicação do teste F. Para localização das diferenças entre os resultados obtidos nos diferentes locais, em cada exposição, foi aplicado o teste de comparações múltiplas de Student-Newman-Keuls, adotando-se $\mathrm{p}<0,05$ como limite de significância. Foram, também, realizados testes de correlação e regressão linear entre o conteúdo de enxofre e parâmetros de crescimento e de biomassa, para estabelecimento do grau de dependência entre essas variáveis.

\section{Resultados}

As plantas expostas no Caminho do Mar (CM), nas proximidades das indústrias petroquímicas de Cubatão, acumularam significativamente o enxofre em suas folhas, após todas as três exposições, sendo medidas concentrações entre $26 \%$ e $85 \%$ superiores às obtidas nas plantas expostas no local controle (RP). Por outro lado, somente nas duas últimas exposições, as concentrações foliares de enxofre foram significativamente maiores (entre $16 \%$ e $65 \%$ ) nas plantas expostas no entorno das indústrias químicas e siderúrgicas do vale do Mogi (VM) do que nas plantas submetidas à situação controle (tabela 2).

Os padrões de crescimento das plantas foram bastante alterados nas plantas introduzidas nos locais poluídos (tabela 3 ). $\mathrm{Na}$ exposição 1 , houve um incremento significativo na altura das plantas expostas no VM $(87 \%$ superior ao incremento encontrado na plantas do local RP) e no número total de folhas das plantas colocadas em ambos os locais poluídos (139\% e $275 \%$ mais folhas nas plantas do CM e VM, respectivamente, em relação à situação controle). $\mathrm{O}$ número total de folhas no caule principal foi reduzido apenas nas plantas do VM (25\% de redução em relação às plantas do RP) e a ramificação das plantas foi significativamente mais intensa em ambos os locais poluídos (67\% e 167\% mais ramos nas plantas do CM e VM, respectivamente, em relação à situação controle). Ao longo da exposição 2, as plantas introduzidas em todos os locais cresceram de modo similar, com exceção daquelas do $\mathrm{CM}$, que cresceram em altura $35 \%$ menos do que as do RP. Na exposição 3, por sua vez, as plantas dos locais CM e VM cresceram mais em altura (35\% e $62 \%$, respectivamente), produziram maior número de folhas ( $83 \%$ e $146 \%)$ e de ramos (75\% e $175 \%)$, porém apresentaram menor número de folhas no caule principal (19\% e 37\%), do que as plantas submetidas aos menores níveis de poluição do RP.

A biomassa de folhas, de caules+ramos e de raízes variou pouco entre as plantas expostas nos três locais de estudo (tabela 4). A biomassa de folhas em plantas provenientes do VM somente foi significativamente maior após a terceira exposição $(30 \%$ em relação ao valor encontrado no local controle) e a de caules + ramos após as exposições 1 e 3 (48\% e 61\%, respectivamente). A biomassa de raízes somente foi menor $(22 \%)$ nas plantas do CM e após a terceira exposição. Nenhuma diferença significativa em biomassa foi encontrada ao término da segunda exposição. No entanto, houve uma redução significativa (entre $22 \%$ e $44 \%$ ) na razão entre biomassa de raízes e biomassa da parte aérea das plantas em exposição nos dois locais poluídos (exposições $1 \mathrm{e}$ 3 , tabela 4).

Análises de correlação de Pearson, mostradas na tabela 5, não revelaram relação significativa entre as concentrações foliares de enxofre e quaisquer das variáveis de crescimento e de biomassa quantificadas após a exposição 1 . Na exposição 2 , no entanto, foi encontrada relação negativa significativa entre o conteúdo foliar de enxofre e o incremento em altura e a 
Tabela 2. Concentrações foliares médias de enxofre (mg. $\mathrm{g}^{-1}$ massa seca) e respectivos desvios padrões (DP), em plantas jovens de Tibouchina pulchra expostas nos diferentes locais e períodos, na região de Cubatão $(\mathrm{n}=10)$. Médias seguidas por letras iguais na coluna, em cada exposição, não são significativamente diferentes (Teste de Student-Newman-Keuls, $\mathrm{p}<0,05$ ). A porcentagem de alteração foi calculada em relação à concentração foliar média obtida em plantas expostas no local controle (RP); ${ }^{(+)}$: aumento significativo.

Table 2. Mean foliar concentrations of sulfur (mg.g ${ }^{-1}$ dry mass), with their standard deviations (DP), in saplings of Tibouchina pulchra exposed in the different sites and periods in Cubatão $(\mathrm{n}=10)$. Mean values followed by the same letter in the column, in each exposure period, are not significantly different (Student-Newman-Keuls test, $p<0.05$ ). The percentage of alteration was calculated in relation to the mean concentration obtained in leaves of plants exposed in the control site (RP); ${ }^{(+)}$: significant increase.

\begin{tabular}{|c|c|c|c|c|c|c|c|c|c|}
\hline \multirow[t]{2}{*}{ Local } & \multicolumn{3}{|c|}{ Exposição 1} & \multicolumn{3}{|c|}{ Exposição 2} & \multicolumn{3}{|c|}{ Exposição 3} \\
\hline & Média & DP & $\begin{array}{c}\text { \% de } \\
\text { alteração }\end{array}$ & Média & DP & $\begin{array}{c}\% \text { de } \\
\text { alteração }\end{array}$ & Média & DP & $\begin{array}{c}\% \text { de } \\
\text { alteração }\end{array}$ \\
\hline $\mathrm{RP}$ & $7,1 \mathrm{~b}$ & 0,9 & - & $6,8 \mathrm{~b}$ & 0,8 & - & $4,0 \mathrm{~b}$ & 0,5 & - \\
\hline $\mathrm{CM}$ & $9,4 \mathrm{a}$ & 1,0 & $32^{(+)}$ & $8,6 \mathrm{a}$ & 0,8 & $26^{(+)}$ & $7,4 \mathrm{a}$ & 1,0 & $85^{(+)}$ \\
\hline VM & $7,8 \mathrm{~b}$ & 1,4 & 10 & $7,8 \mathrm{a}$ & 0,9 & $16^{(+)}$ & $6,6 \mathrm{a}$ & 0,4 & $65^{(+)}$ \\
\hline
\end{tabular}

biomassa de caules+ramos e de raízes. $\mathrm{Na}$ exposição 3 , as concentrações foliares de enxofre correlacionaram-se negativamente com o número de folhas no caule principal, com a biomassa de raízes e com a razão de biomassa raiz/parte aérea e positivamente com o incremento em altura e em número total de folhas e com o número final de ramos.

As relações significativas encontradas nas exposições 2 e 3 foram a base para determinação, através de análises de regressão linear, dos coeficientes de explicação entre as variáveis de crescimento e concentrações foliares de enxofre, as quais encontramse representadas graficamente nas figuras 2 e 3 . As análises de regressão indicaram que a desaceleração do crescimento em altura $(p=0,01)$ e a diminuição na biomassa de caules+ramos $(p=0,04)$ e de raízes $(\mathrm{p}=0,01)$ ao longo da exposição 2 (figura 2) e a intensificação do crescimento em altura, da produção de folhas e da ramificação, assim como a redução no número final de folhas no caule principal, na biomassa de raízes e na razão de biomassa raiz/parte aérea $(\mathrm{p}<0,01$ ), durante a exposição 3 (figura 3 ) foram explicadas significativamente pelo aumento nas concentrações foliares de enxofre.

\section{Discussão}

O acúmulo foliar de enxofre encontrado nas plantas de Tibouchina pulchra em exposição no Caminho do Mar, durante todo o período de estudo, sugere que houve absorção via estômatos de compostos gasosos de enxofre, especialmente $\mathrm{SO}_{2}$, emitidos durante as atividades de produção de energia e vapor das indústrias petroquímicas lá instaladas. No vale do Mogi, onde indústrias químicas e siderúrgicas estão em operação, a contaminação do ar por $\mathrm{SO}_{2}$ de modo a induzir acúmulo foliar de enxofre só ocorreu nos últimos oito meses de estudo. Tal acúmulo foliar de enxofre em plantas expostas a imissões fitotóxicas de $\mathrm{SO}_{2}$ é, de fato, freqüentemente mencionado por diversos autores, entre eles Dmuchowski \& Bylnerowicz (1995), Klumpp et al. (2001), Krupa \& Legge (2001), como resultado da absorção estomática durante as trocas gasosas.

Ressalta-se que, embora o caminho natural para absorção de enxofre pelas plantas seja por meio das raízes, os maiores níveis de enxofre encontrados nas plantas, no presente estudo, devem ter sido provenientes da atmosfera contaminada por compostos sulfurosos, já que todas as plantas utilizadas nas exposições foram cultivadas em solo com a mesma procedência, eliminando-se possíveis variações iniciais na disponibilidade de enxofre no solo que pudessem proporcionar maior ou menor na absorção do elemento por via radicial. Não se pode descartar a possibilidade de os compostos atmosféricos terem sido incorporados na forma de sulfatos no solo dos vasos em exposição, através de deposição seca ou úmida, tornando-se disponíveis para absorção via raízes. Mesmo nesse caso, a fonte de enxofre seria a atmosfera. Contudo, com a metodologia adotada no presente estudo, não foi possível 
Tabela 3. Valores médios de incremento em altura e em número total de folhas (\% do valor inicial) e número de folhas no caule principal e de ramos (após a exposição), com respectivos desvios padrões (DP), em plantas jovens de Tibouchina pulchra expostas nos diferentes locais e períodos, na região de Cubatão $(\mathrm{n}=10)$. Médias seguidas por letras iguais na coluna, em cada exposição e para cada variável de crescimento, não são significativamente diferentes (Teste de Student-Newman-Keuls, $\mathrm{p}<0,05)$. A porcentagem de alteração foi calculada em relação ao valor médio obtido em plantas expostas no local controle $(\mathrm{RP}) ;{ }^{(+)}$: aumento significativo; ${ }^{(-)}$redução significativa.

Table 3. Mean increment in the height and in the total number of leaves ( $\%$ of initial value) and number of leaves in the main stem, with their standard deviations (DP), in saplings of Tibouchina pulchra exposed in the different sites and periods in Cubatão $(n=10)$. Mean values followed by the same letter in the column, in each exposure period and for each growth variable, are not significantly different (Student-Newman-Keuls test, $\mathrm{p}<0.05$ ). The percentage of alteration was calculated in relation to the mean value obtained in plants exposed in the control site (RP); ${ }^{(+)}$: significant increase; ${ }^{(-)}$significant decrease.

\begin{tabular}{|c|c|c|c|c|c|c|c|c|c|}
\hline \multirow[t]{2}{*}{ Local } & \multicolumn{3}{|c|}{ Exposição 1} & \multicolumn{3}{|c|}{ Exposição 2} & \multicolumn{3}{|c|}{ Exposição 3} \\
\hline & Média & DP & $\begin{array}{c}\% \text { de } \\
\text { alteração }\end{array}$ & Média & $\mathrm{DP}$ & $\begin{array}{c}\% \text { de } \\
\text { alteração }\end{array}$ & Média & $\mathrm{DP}$ & $\begin{array}{c}\% \text { de } \\
\text { alteração }\end{array}$ \\
\hline \multicolumn{10}{|c|}{ Incremento em altura } \\
\hline $\mathrm{RP}$ & $31 \mathrm{~b}$ & 6 & - & $60 a$ & 10 & - & $34 \mathrm{~b}$ & 7 & - \\
\hline $\mathrm{CM}$ & $36 \mathrm{~b}$ & 3 & 16 & $39 \mathrm{~b}$ & 10 & $35^{(-)}$ & $46 \mathrm{a}$ & 14 & $35^{(+)}$ \\
\hline $\mathrm{VM}$ & $58 \mathrm{a}$ & 10 & $87^{(+)}$ & $52 \mathrm{a}$ & 12 & 15 & $55 \mathrm{a}$ & 7 & $62^{(+)}$ \\
\hline \multicolumn{10}{|c|}{ Incremento em número total de folhas } \\
\hline $\mathrm{RP}$ & $108 \mathrm{c}$ & 46 & - & $500 \mathrm{a}$ & 278 & - & $253 \mathrm{c}$ & 63 & - \\
\hline $\mathrm{CM}$ & $258 \mathrm{~b}$ & 83 & $139^{(+)}$ & $530 \mathrm{a}$ & 342 & 6 & $464 \mathrm{~b}$ & 196 & $83^{(+)}$ \\
\hline $\mathrm{VM}$ & $405 \mathrm{a}$ & 92 & $275^{(+)}$ & $563 \mathrm{a}$ & 188 & 13 & $623 \mathrm{a}$ & 137 & $146^{(+)}$ \\
\hline \multicolumn{10}{|c|}{ Número de folhas no caule principal } \\
\hline $\mathrm{RP}$ & $12 \mathrm{a}$ & 2 & - & $13 \mathrm{a}$ & 2 & - & $16 \mathrm{a}$ & 2 & - \\
\hline $\mathrm{CM}$ & $11 \mathrm{ab}$ & 3 & 8 & $12 \mathrm{a}$ & 2 & 8 & $13 \mathrm{~b}$ & 2 & $19^{(-)}$ \\
\hline VM & $9 \mathrm{~b}$ & 2 & $25^{(-)}$ & $10 \mathrm{a}$ & 1 & 23 & $10 \mathrm{c}$ & 1 & $37^{(-)}$ \\
\hline \multicolumn{10}{|c|}{ Número de ramos } \\
\hline $\mathrm{RP}$ & $3 \mathrm{c}$ & 2 & - & $6 \mathrm{a}$ & 1 & - & $4 \mathrm{c}$ & 1 & - \\
\hline $\mathrm{CM}$ & $5 \mathrm{~b}$ & 1 & $67^{(+)}$ & $5 \mathrm{a}$ & 2 & 17 & $7 \mathrm{~b}$ & 3 & $75^{(+)}$ \\
\hline VM & $8 \mathrm{a}$ & 2 & $167^{(+)}$ & $7 \mathrm{a}$ & 1 & 17 & $11 \mathrm{a}$ & 3 & $175^{(+)}$ \\
\hline
\end{tabular}

estabelecer em que proporção o enxofre atmosférico foi incorporado ao solo e absorvido pelas raízes.

Os resultados ora obtidos mostram, ainda, que as imissões desses compostos gasosos em 1997 provavelmente permaneceram nos mesmos níveis observados entre 1992 e 1993, nos dois locais poluídos, quando plantas jovens $T$. pulchra cultivadas e expostas de modo similar acumularam enxofre em suas folhas na mesma proporção, em média 9,0 e $8,6 \mathrm{mg} \mathrm{g}^{-1}$ de massa seca, respectivamente nos locais $\mathrm{CM}$ e VM, valores significativamente mais altos do que 5,3 $\mu \mathrm{g} \cdot \mathrm{g}^{-1}$ de massa seca obtidos nas plantas colocadas no local controle (Klumpp et al. 2002).

Os resultados do presente estudo colocam em cheque os do monitoramento da qualidade do ar realizado continuamente pela Cetesb em suas duas estações fixas de Cubatão (E1 e E2 - figura 1). Tomando por base os limites de concentração estabelecidos por lei brasileira para proteção da saúde humana, fauna e flora (Cetesb 2001), as concentrações médias de $\mathrm{SO}_{2}$ no ar, registradas para os períodos de exposição (tabela 1), embora superiores às registradas no vale do Pilões por Jaeschke (1997) $\left(6,7 \mu \mathrm{m} . \mathrm{m}^{-3}\right.$, em média para os anos de 1991-1995), não são consideradas tóxicas aos sistemas biológicos. Porém, as concentrações médias de $70 \mu \mathrm{g} \mathrm{SO}_{2} \cdot \mathrm{m}^{-3}$ por um dia e de $150 \mu \mathrm{g} \mathrm{SO}_{2} \cdot \mathrm{m}^{-3}$ por uma hora, limites para proteção de florestas e de espécies arbóreas (Erisman et al. 1998) foram ultrapassadas várias vezes nos dois locais poluídos, especialmente no Caminho do Mar onde foi verificado acúmulo foliar mais acentuado. Portanto, considerando esses limites, as plantas expostas nesses locais estiveram 
Tabela 4. Valores médios de biomassa de folhas, caules+ramos e raízes ( $\mathrm{g}$ de massa seca) e razão entre biomassa de raízes e biomassa da parte aérea (raiz/parte aérea), com respectivos desvios padrões (DP), em plantas jovens de Tibouchina pulchra expostas nos diferentes locais e períodos, na região de Cubatão $(\mathrm{n}=10)$. Médias seguidas por letras iguais na coluna, em cada exposição e para cada variável de biomassa, não são significativamente diferentes (Teste de Student-Newman-Keuls, $\mathrm{p}<0,05$ ). A porcentagem de alteração foi calculada em relação ao valor médio obtido em plantas expostas na localidade controle (RP); ${ }^{(+)}$: acréscimo significativo; ${ }^{(-)}$: decréscimo significativo.

Table 4. Mean biomass of leaves, stem+branches and roots (g of dry mass) and root to shoot biomass ratio (root/shoot), with their standard deviations (DP), in saplings of Tibouchina pulchra exposed in the different sites and periods in Cubatão $(\mathrm{n}=10)$. Mean values followed by the same letter in the column, in each exposure period and for each biomass variable, are not significantly different (Student-Newman-Keuls test, $\mathrm{p}<0.05$ ). The percentage of alteration was calculated in relation to the mean value obtained in plants exposed in the control site (RP); ${ }^{(+)}$: significant increase ${ }^{(-)}$significant decrease.

\begin{tabular}{|c|c|c|c|c|c|c|c|c|c|}
\hline \multirow[t]{2}{*}{ Local } & \multicolumn{3}{|c|}{ Exposição 1} & \multicolumn{3}{|c|}{ Exposição 2} & \multicolumn{3}{|c|}{ Exposição 3} \\
\hline & Média & $\mathrm{DP}$ & $\begin{array}{c}\% \text { de } \\
\text { alteração }\end{array}$ & Média & $\mathrm{DP}$ & $\begin{array}{c}\% \text { de } \\
\text { alteração }\end{array}$ & Média & DP & $\begin{array}{c}\% \text { de } \\
\text { alteração }\end{array}$ \\
\hline \multicolumn{10}{|c|}{ Biomassa de folhas } \\
\hline $\mathrm{RP}$ & $3,0 \mathrm{a}$ & 0,7 & - & $4,6 \mathrm{a}$ & 1,3 & - & $5,4 \mathrm{~b}$ & 1,0 & - \\
\hline $\mathrm{CM}$ & $3,3 \mathrm{a}$ & 0,6 & 10 & $4,5 \mathrm{a}$ & 1,3 & 2 & $6,0 \mathrm{ab}$ & 1,4 & 11 \\
\hline $\mathrm{VM}$ & $3,8 \mathrm{a}$ & 0,9 & 27 & $4,6 \mathrm{a}$ & 0,8 & 0 & $7,0 \mathrm{a}$ & 1,7 & $30^{(+)}$ \\
\hline \multicolumn{10}{|c|}{ Biomassa de caules + ramos } \\
\hline $\mathrm{RP}$ & $2,3 \mathrm{~b}$ & 0,7 & - & $3,6 \mathrm{a}$ & 0,7 & - & $4,1 \mathrm{~b}$ & 0,6 & - \\
\hline $\mathrm{CM}$ & $2,6 \mathrm{~b}$ & 0,4 & 13 & $3,3 \mathrm{a}$ & 0,7 & 8 & $4,9 \mathrm{~b}$ & 1,1 & 19 \\
\hline $\mathrm{VM}$ & $3,4 \mathrm{a}$ & 1,0 & $48^{(+)}$ & $4,2 \mathrm{a}$ & 1,1 & 17 & $6,6 \mathrm{a}$ & 1,8 & $61^{(+)}$ \\
\hline \multicolumn{10}{|c|}{ Biomassa de raízes } \\
\hline $\mathrm{RP}$ & $4,8 \mathrm{a}$ & 1,6 & - & $4,1 \mathrm{a}$ & 1,3 & - & $6,4 \mathrm{a}$ & 1,3 & - \\
\hline $\mathrm{CM}$ & $4,3 \mathrm{a}$ & 1,4 & 12 & $3,6 \mathrm{a}$ & 0,9 & 12 & $4,9 \mathrm{~b}$ & 1,0 & $22^{(-)}$ \\
\hline $\mathrm{VM}$ & $3,8 \mathrm{a}$ & 1,2 & 22 & $3,9 a$ & 1,1 & 5 & $5,3 \mathrm{ab}$ & 1,5 & 17 \\
\hline \multicolumn{10}{|c|}{ Raiz/parte aérea } \\
\hline $\mathrm{RP}$ & $0,9 \mathrm{a}$ & 0,1 & - & $0,5 \mathrm{a}$ & 0,1 & - & $0,7 \mathrm{a}$ & 0,1 & - \\
\hline $\mathrm{CM}$ & $0,7 \mathrm{~b}$ & 0,2 & $22^{(-)}$ & $0,5 \mathrm{a}$ & 0,1 & 0 & $0,5 \mathrm{~b}$ & 0,1 & $29^{(-)}$ \\
\hline $\mathrm{VM}$ & $0,5 \mathrm{c}$ & 0,1 & $44^{(-)}$ & $0,4 \mathrm{a}$ & 0,0 & 20 & $0,4 \mathrm{~b}$ & 0,0 & $43^{(-)}$ \\
\hline
\end{tabular}

sob a influência de concentrações de $\mathrm{SO}_{2}$ potencialmente fitotóxicas.

Há que se considerar, também, que as plantas estiveram, objetivamente, submetidas a concentrações de $\mathrm{SO}_{2}$ mais altas do que as registradas em ambas as estações de monitoramento da Cetesb. Isso porque os pontos de exposição das plantas estavam muito mais próximos às fontes emissoras do Caminho do Mar e do vale do Mogi, recebendo constantemente ventos carregados de poluentes, mais do que as estações de monitoramento da Cetesb. Ressalta-se que as estações de monitoramento foram instaladas para avaliar a qualidade do ar em locais onde há maior concentração de pessoas (Centro e Bairro Vila Parisi de Cubatão) e não exatamente onde provavelmente ocorrem as concentrações máximas de poluentes, entre as indústrias e a vegetação que recobre as encostas da Serra do
Mar. Jaeschke (1997), a partir de medidas descontínuas utilizando sistema de sensoreamento remoto com laser, chegou a registrar valores momentâneos de concentração de $\mathrm{SO}_{2}$ tão altos quanto $3 \mathrm{mg} \cdot \mathrm{m}^{-3}$ sobre as encostas da Serra do Mar, no Caminho do Mar, onde estava instalado o sistema de exposição das plantas do presente estudo. Assim, comparações muito estreitas entre os dados disponíveis da Cetesb sobre imissões de $\mathrm{SO}_{2}$ e o acúmulo de enxofre nas folhas das plantas devem ser interpretadas com cautela.

Além disso, a concentração de um elemento em folhas é uma medida relativa entre a quantidade absorvida do elemento e a quantidade de biomassa produzida, podendo haver uma diluição do elemento no interior de uma planta que apresentar intenso crescimento. Esse efeito da diluição pode ser verificado no presente estudo, na terceira exposição, período em 
Tabela 5. Coeficientes de correlação de Pearson entre concentrações foliares de enxofre e variáveis de crescimento e de biomassa, considerando o conjunto de dados obtidos para plantas expostas nos três locais de Cubatão, em cada exposição $(\mathrm{n}=30)$.

Table 5. Correlation coefficients of Pearson between foliar concentrations of sulfur and growth and biomass variables, considering all data obtained for the plants exposed in the three sites of Cubatão in each exposure period $(n=30)$.

\begin{tabular}{lccc}
\hline Indicadores de crescimento & Exposição 1 & Exposição 2 & Exposição 3 \\
\hline Incremento em altura & $0,07^{\mathrm{ns}}$ & $-0,51^{*}$ & $0,56^{*}$ \\
Incremento em n. total de folhas & $0,14^{\mathrm{ns}}$ & $0,14^{\mathrm{ns}}$ & $0,63^{*}$ \\
N. de folhas no caule principal & $-0,08^{\mathrm{ns}}$ & $-0,12^{\mathrm{ns}}$ & $-0,60^{*}$ \\
N. de ramos & $0,21^{\mathrm{ns}}$ & $-0,03^{\mathrm{ns}}$ & $0,58^{*}$ \\
Biomassa de folhas & $0,24^{\mathrm{ns}}$ & $-0,32^{\mathrm{ns}}$ & $0,23^{\mathrm{ns}}$ \\
Biomassa de caules +ramos & $0,14^{\mathrm{ns}}$ & $-0,43^{*}$ & $0,35^{\mathrm{ns}}$ \\
Biomassa de raízes & $0,00^{\mathrm{ns}}$ & $-0,50^{*}$ & $-0,46^{*}$ \\
Raiz/parte aérea & $-0,19^{\mathrm{ns}}$ & $-0,22^{\mathrm{ns}}$ & $-0,73^{*}$ \\
\hline
\end{tabular}

${ }^{*}$ Coeficiente de correlação significativo ao nível de $5 \%$ de probabilidade; ns Coeficiente de correlação não significativo ao nível de $5 \%$ de probabilidade.

que foram registrados alto índice pluviométrico e altas temperaturas e umidade, condições climáticas favoráveis à maior produção de biomassa foliar (tabela 4). Porém, apesar dessa diluição, o efeito do excesso de enxofre sobre o crescimento da planta foi mais acentuado nessa última exposição do que nas demais (tabela 5, figura 3), possivelmente devido à maior intensidade dos processos fisiológicos e metabólicos nas plantas no período de maior crescimento. Nessa situação, é esperado, também, aumento na absorção de compostos de enxofre presentes no ar.

Os coeficientes de determinação $\left(\mathrm{r}^{2}\right)$ incluídos nas figuras 2 e 3 revelaram que a variação no acúmulo foliar de enxofre, como resultado da absorção estomática de óxidos de enxofre, explicou significativamente entre $18 \%$ e $54 \%$ das variações nos padrões de crescimento de plantas jovens de T. pulchra expostas na região de Cubatão, nos últimos oito meses de estudo.

As reações das plantas ao estresse induzido por óxidos de enxofre, relativas ao crescimento, são bastante distintas e dependem da espécie, da arquitetura e grau de resistência da planta, das doses de exposição, do estado nutricional, entre outros fatores (Deepak \& Agrawal 2001). Porém, é freqüente encontrar, na literatura, menção sobre a existência das relações entre acúmulo foliar de enxofre e parâmetros de crescimento e de biomassa, encontradas neste estudo, em plantas submetidas a doses crônicas de $\mathrm{SO}_{2}$, reforçando as conclusões obtidas em condições de campo em Cubatão.

Os efeitos do $\mathrm{SO}_{2}$ sobre a altura das plantas têm sido bastante distintos. Enquanto Murray et al. (1992) e Holland et al. (1995) não verificaram nenhum efeito na altura de plantas de Araucaria cunninghamii
D. Don e de coníferas arbóreas tratadas com $\mathrm{SO}_{2}$, Fulford \& Murray (1990) registraram uma intensificação no crescimento em altura de plantas de Eucalyptus gomphocephala DC., porém sem aumento da biomassa da parte aérea e Deepak \& Agrawal (1999, 2001) observaram redução significativa na altura de trigo e de cultivares de soja. Tais respostas antagônicas, também observadas no presente estudo, podem ser atribuídas a mudanças na alocação de fotoassimilados, passíveis de identificação a partir do cálculo de razões entre peso de raízes e da parte aérea da planta, ou a alterações do metabolismo no ápice do caule, segundo Fulford \& Murray (1990).

Queda prematura de folhas, aumento da produção de folhas e da ramificação, redução na biomassa de raízes e de caules e diminuição da alocação de biomassa para as raízes em relação à alocação para as folhas, caules e ramos, observados no presente estudo, são reações compensatórias comumente verificadas em plantas expostas ao $\mathrm{SO}_{2}$ e foram mencionadas, por exemplo, por Fulford \& Murray (1990), Clarke \& Murray (1990), Murray et al. (1992), Dodd \& Doley (1998) e Deepak \& Agrawal (1999, 2001).

Shaw \& McLeod (1995), entre outros autores, mencionam que é possível se verificar o chamado efeito fertilizante em plantas submetidas a doses baixas de $\mathrm{SO}_{2}$, resultando em aumento em seu crescimento, já que o enxofre é um nutriente essencial às plantas. Esse fenômeno pode ter ocorrido durante a terceira exposição, quando incrementos significativos em altura e em biomassa foram observados especialmente nas plantas no vale do Mogi. Mas, nessa mesma exposição, houve nítida mudança na arquitetura da planta (maiores 

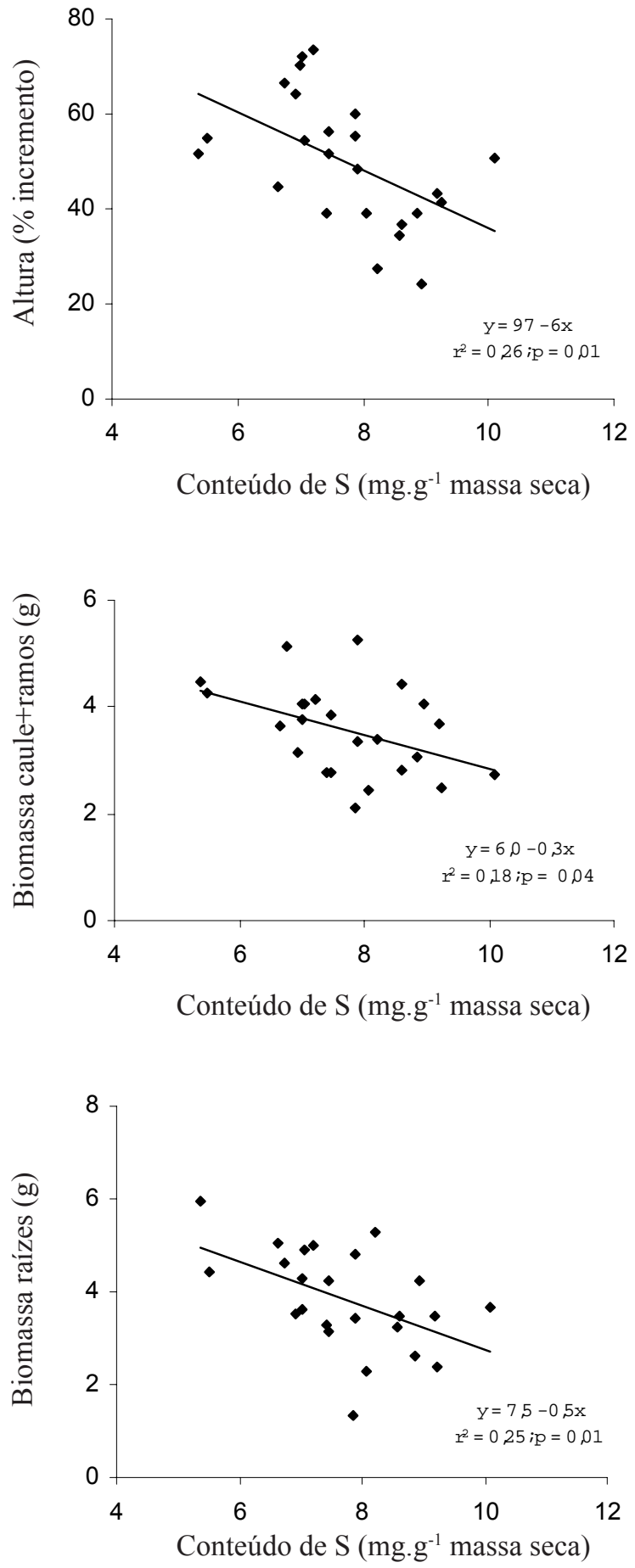

Figura 2. Análises de regressão linear, com as respectivas equações da reta e valores de $\mathrm{r}^{2}$ e $\mathrm{p}$, entre o conteúdo foliar de enxofre e altura (A), biomassa de caule+ramos (B) e biomassa de raízes $(\mathrm{C})$, em plantas jovens de Tibouchina pulchra mantidas nos diferentes locais durante a exposição $2(n=30)$.

Figure 2. Linear regression analyses, with their equations and $r^{2}$ and $p$ values, between sulfur accumulation in leaves and height (A), biomass of stem + branches (B) and biomass of roots (C), in saplings of Tibouchina pulchra maintained in the different experimental sites during the exposure period $2(n=30)$.
A ramificação, produção de folhas nos ramos laterais e queda de folhas no caule principal) e na razão de biomassa raiz/parte aérea, que são reações adversas comumente observadas em plantas ao estresse induzido por $\mathrm{SO}_{2}$. Assim, o efeito fertilizante nessa exposição parece ter sido sobrepujado pelos efeitos negativos.

É preciso lembrar que as plantas submetidas a doses tóxicas de um poluente, em condições de campo, nunca mostram reações exclusivas ao mesmo, como ocorre em experimentos controlados de fumigação, em que todos os demais fatores ambientais que possam interferir na resposta da planta em estudo são controlados. No campo, as reações observadas são sempre resultado da ação de um conjunto de fatores ambientais, incluindo as doses tóxicas do poluente. Essas doses podem ser altíssimas e as reações vegetais mínimas, se as plantas estiverem sob condições climáticas desfavoráveis para manutenção de estômatos abertos. Nesse caso, as trocas gasosas seriam mínimas e a absorção do poluente gasoso também. Esse fato pode ter ocorrido durante a exposição 2 (período de inverno), quando as condições climáticas foram menos favoráveis ao crescimento e à absorção de $\mathrm{SO}_{2}$, apesar deste estar mais concentrado na atmosfera, resultando em poucas interferências no crescimento das plantas nos locais poluídos, em comparação com o que ocorreu no local controle (tabelas 1, 3, 4). O princípio básico da bioindicação baseia-se justamente nessas reações vegetais integradas, sendo perfeitamente aceitável a observação de respostas antagônicas de uma mesma espécie exposta em um ambiente poluído, como ocorreu no presente estudo para o parâmetro altura.

Os resultados obtidos, ao mostrarem até que ponto o acúmulo foliar de enxofre teve relação com alterações no crescimento em plantas jovens de T. pulchra, confirmaram a hipótese de que as concentrações de $\mathrm{SO}_{2}$ no ar, apesar de estarem bem abaixo dos limites estabelecidos em legislação com vistas à proteção da flora, fauna e saúde humana, ainda contribuem, juntamente com outros fatores de estresse como os níveis tóxicos de outros poluentes gasosos (óxidos de nitrogênio, fluoretos, compostos orgânicos, entre outros), para aumentar os riscos impostos às plantas de $T$. pulchra na região do complexo industrial de Cubatão.

Agradecimentos - À Fundação de Amparo a Pesquisa do Estado de São Paulo pela concessão da bolsa de mestrado para a primeira autora (proc. Fapesp n. 97/07715-0). 


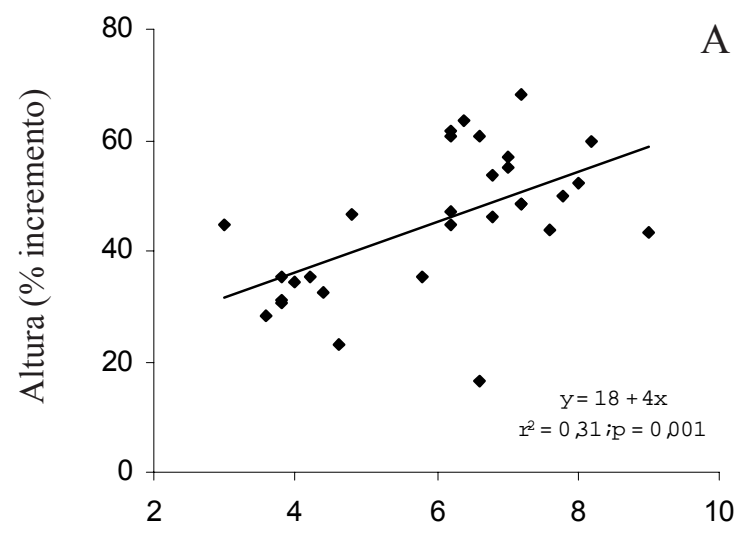

Conteúdo de S (mg.g-1 massa seca)

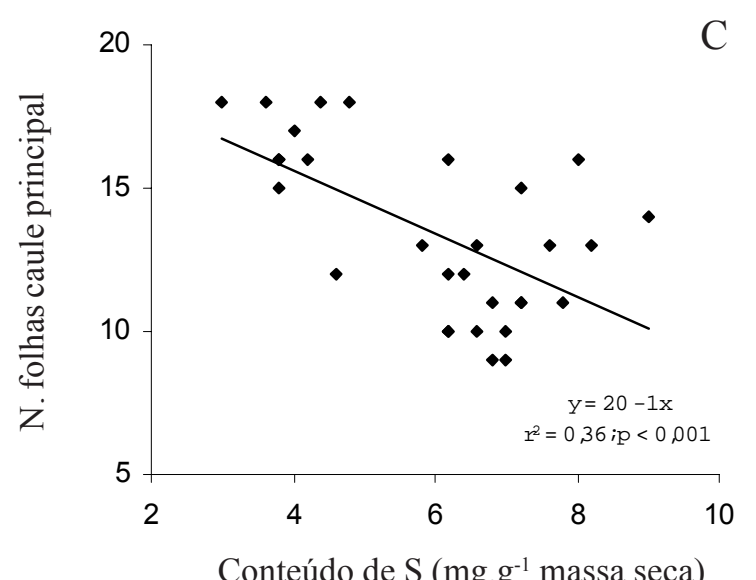

Conteúdo de $\mathrm{S}$ (mg.g $\mathrm{g}^{-1}$ massa seca)

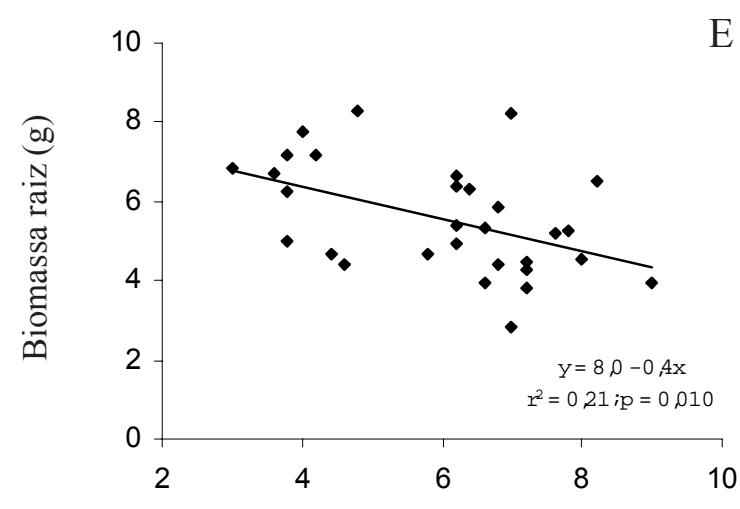

Conteúdo de S (mg.g-1 massa seca)

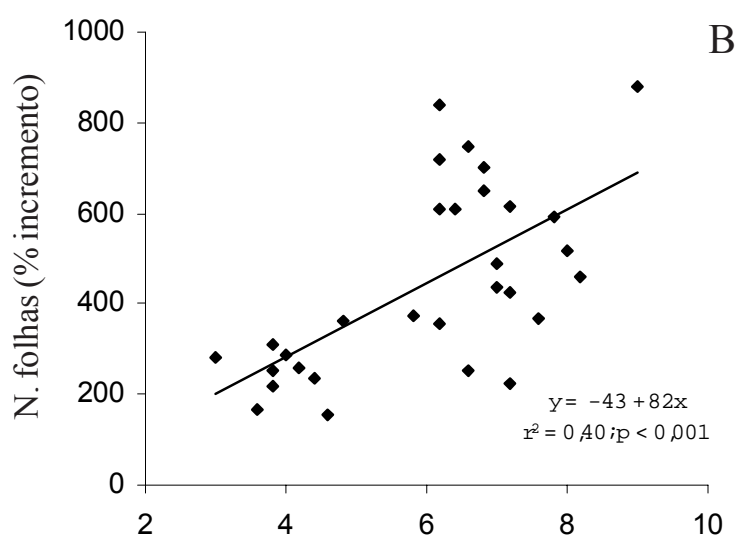

Conteúdo de $\mathrm{S}$ (mg.g-1 massa seca)
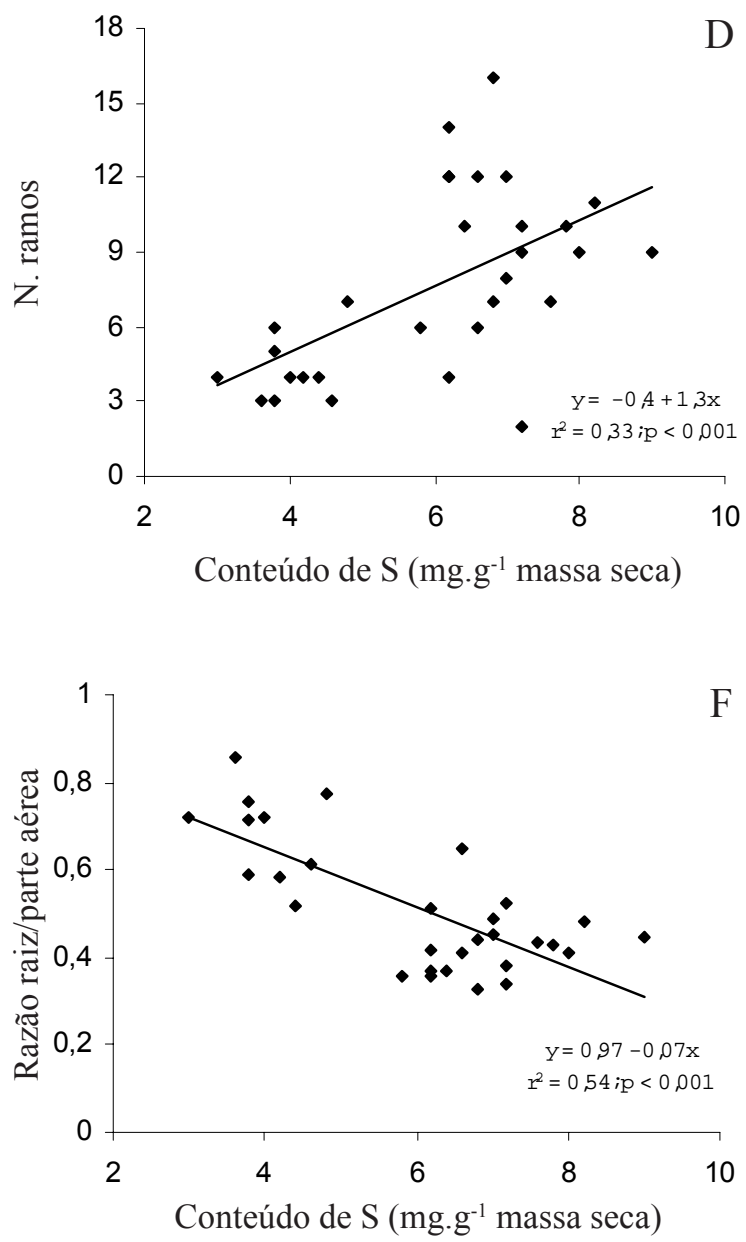

Figura 3. Análises de regressão linear, com os respectivos valores de $\mathrm{r}^{2}$ e $\mathrm{p}$, entre o conteúdo foliar de enxofre e altura (A), número total de folhas $(\mathrm{B})$, de folhas no caule principal (C) e de ramos (D), biomassa de raízes (E) e razão de biomassa entre raízes e parte aérea (F), em plantas jovens de Tibouchina pulchra mantidas nos diferentes locais durante a exposição 3 (n=30).

Figure 3. Linear regression analyses, with their equations and $\mathrm{r}^{2}$ and $\mathrm{p}$ values, between sulfur accumulation in leaves and height (A), total number of leaves (B), number of leaves in the main stem (C), number of branches (D), biomass of roots (E) and root to shoot biomass ratio $(\mathrm{F})$, in saplings of Tibouchina pulchra maintained in the different experimental sites during the exposure period $3(n=30)$. 


\section{Referências bibliográficas}

ALONSO, C.D. \& GODINHO, R. 1992. A evolução da qualidade do ar em Cubatão. Química Nova 15:126-136.

ARNDT, U. \& SCHWEIZER, B. 1991. The use of bioindicators for environmental monitoring in tropical and subtropical countries. In Biological monitoring. Signals from the environment (H. Ellenberg, ed.). Vieweg, Braunschweig, p.199-260.

BUTTERS, B. \& CHENERY, E.M. 1959. A rapid method for the determination of total sulphur in soils and plants. Analyst 84:239-245.

CETESB. 2001. Relatório de qualidade do ar no Estado de São Paulo - 2000. Série relatórios. Companhia de Tecnologia de Saneamento Ambiental, São Paulo.

CLARKE, K. \& MURRAY, F. 1990. Stimulatory effects of $\mathrm{SO}_{2}$ on growth of Eucalyptus rudis Endl. The New Phytologist 115:633-637.

DEEPAK, S.S. \& AGRAWAL, M. 1999. Growth and yield responses of wheat plants to elevated levels of $\mathrm{CO}_{2}$ and $\mathrm{SO}_{2}$, singly and in combination. Environmental Pollution 104:411-419.

DEEPAK, S.S. \& AGRAWAL, M. 2001. Influence of elevated $\mathrm{CO}_{2}$ on the sensitivity of two soybean cultivars to sulphur dioxide. Environmental and Experimental Botany 46:81-91.

DMUCHOWSKI, W. \& BYLNEROWICZ, A. 1995. Monitoring environmental pollution in Polland by chemical analysis of scots pine (Pinus sylvestris L.) needles. Environmental Pollution 87:87-104.

DODD, I.C. \& DOLEY, D. 1998. Growth responses of cucumber seedlings to sulphur dioxide fumigation in a tropical environment. Environmental and Experimental Botany 39:41-47.

DOMINGOS, M., KLUMPP, A. \& KLUMPP, G. 1998. Air pollution impact on the Atlantic forest in the Cubatão region, SP, Brazil. Ciência e Cultura 50:230-236.

ERISMAN, J.W., DRAAIJERS, G.P.J., STEINGRÖVER, E., VAN DIJK, H., BOXMAN, A. \& DE VRIES, W. 1998. Assessment of the exposure and loads of acidifying and eutrophying pollutants and ozone, as well as their harmful influence on the vitality of the trees and the speulder forest ecosystem as a whole. Water, Air and Soil Pollution 105:539-571.

FULFORD, G.B. \& MURRAY, F. 1990. Morphogenic changes in Eucalyptus gomphocephala exposed to $\mathrm{SO}_{2}$. Environmental and Experimental Botany 30:343-347.

HOLLAND, M.R., MUELLER, P.W., RUTTER, A.J. \& SHAW, P.J.A. 1995. Growth of coniferous trees exposed to $\mathrm{SO}_{2}$ and $\mathrm{O}_{3}$ using an open-air fumigation system. Plant, Cell and Environment 18:227-236.

JAESCHKE, W. 1997 (resp.). Chemistry module. In Air pollution and vegetation damage in the tropics - the Serra do Mar as an example - Final report 1990-1996 (D. Klockow, H.T. Targa \& W. Vautz, eds.). GKSS Forschungszentrum Geesthacht $\mathrm{GmbH}$, Geesthacht, p.III.1- II.77.
KLUMPP, A., ANSEL, W., KLUMPP, G. \& FOMIN, A. 2001. Um novo conceito de monitoramento e comunicação ambiental: a rede européia para avaliação da qualidade do ar usando plantas bioindicadoras (EuroBioNet). Revista Brasileira de Botânica 24:511-518.

KLUMPP, A., DOMINGOS, M., \& KLUMPP, G. 2002. Foliar nutrient contents in tree species of the Atlantic Forest as influenced by air pollution from the industrial complex of Cubatão, SE-Brazil. Water, Air and Soil Pollution 133:315-333.

KLUMPP, A., KLUMPP, G. \& DOMINGOS, M. 1994. Plants as bioindicators of air pollution at the Serra do Mar near the industrial complex of Cubatão, Brazil. Environmental Pollution 85:09-116.

KLUMPP, A., KLUMPP, G., DOMINGOS, M. \& SILVA, M.D. 1996. Fluoride impact on native tree species of the Atlantic Forest near Cubatão, Brazil. Water, Air and Soil Pollution 87:57-71.

KLUMPP, G., FURLAN, C.M., DOMINGOS, M. \& KLUMPP, A. 2000. Response of stress indicators and growth parameters of Tibouchina pulchra Cogn. exposed to air and soil pollution near the industrial complex of Cubatão, Brazil. The Science of the Total Environment 246:79-91.

KRUPA, S.V. \& LEGGE, A.H. 2001. Sakatoon serviceberry and ambient sulfur dioxide exposures: study sites re-visited, 1999. Environmental Pollution 111:363-365.

MANNINEN, S. \& HUTTUNEN, S. 2000. Response of needle sulphur and nitrogen concentrations of Scots pine versus Norway spruce to $\mathrm{SO}_{2}$ and $\mathrm{NO}_{2}$. Environmental Pollution 107:421-436.

MANNINEN, S., HUTTUNEN, S., RAUTIO, P. \& RERÄMÄKI, P. 1996. Assessing the critical levels of $\mathrm{SO}_{2}$ for Scots pine in situ. Environmental Pollution 93:24-38.

MORAES, R.M., DELITTI, W.B.C. \& MORAES, J.A.P.V. 2000. Respostas de indivíduos jovens de Tibouchina pulchra Cogn. à poluição aérea de Cubatão, SP: fotossíntese, crescimento e química foliar. Revista Brasileira de Botânica 23:443-449.

MURRAY, F. CLARKE, K. \& WILSON, S. 1992. Effects of $\mathrm{NO}_{2}$ on hoop pine can be counteracted by $\mathrm{SO}_{2}$. European Journal of Forest Pathology 22:403-409.

SCHMIEDEN, U. \& WILD, A. 1995. The contribution of ozone to forest decline. Physiologia Plantarum 94:371-378.

SLOVIK, S., HÜVE, K., KINDERMANN, G. \& KAISER, W.M. 1996. $\mathrm{SO}_{2}$ - dependent cation competition and compartmentalization in Norway spruce needles. Plant, Cell and Environment 19:813-824.

SLOVIK, S., SIEGMUND, A., KINDERMANN, G., RIEBELING, R. \& BALÁZS, A. 1995. Stomatal $\mathrm{SO}_{2}$ uptake and sulfate accumulation in needles of norway spruce stands (Picea abies) in Central Europe. Plant and Soil 168/169:405-419.

SHAW, P.J.A., \& MCLEOD, A.R. 1995. The effects of $\mathrm{SO}_{2}$ and $\mathrm{O}_{3}$ on the foliar nutrition of Scots pine, Norway spruce and Sitka spruce in the Liphook open-air fumigation experiment. Plant, Cell and Environment 18:237-245. 